\title{
CONSTITUCIONALISMO SOCIAL COMO DEMOCRACIA ECONÓMICA. UNA RELECTURA DE LA CONSTITUCIÓN DE WEIMAR A LA LUZ DEL APORTE DE HUGO SINZHEIMER*
}

\section{SOCIAL CONSTITUCIONALISM AS ECONOMIC DEMOCRACY. A REINTERPRETATION OF THE WEIMAR CONSTITUCION IN THE LIGHT OF HUGO SINZHEIMER'S CONTRIBUTION}

\author{
Leticia Vita \\ Universidad de Buenos Aires - CONICET (Argentina)
}

\begin{abstract}
SUMARIO: I. INTRODUCCIÓN. II. EL TRABAJO DE LA ASAMBLEA NACIONAL DE WEIMAR EN LA LITERATURA ESPECIALIZADA. III. LA ASAMBLEA NACIONAL DE WEIMAR EN ACCIÓN. 1. La figura de Hugo Sinzheimer en tiempos de la República. 2. La Propuesta Socialdemócrata para un Estado social. IV. CONSTITUCIONALISMO SOCIAL COMO DEMOCRACIA ECONÓMICA. V.
\end{abstract} CONCLUSIONES. VI. BIBLIOGRAFÍA.

Resumen: Este artículo tiene como objetivo revisar el trabajo de la Asamblea Nacional de Weimar y en particular el de uno de sus diputados, Hugo Sinzheimer, a fin de reinterpretar el alcance del tipo de constitucionalismo social que se diseñó en la Alemania de 1919. Se parte del supuesto de que el trabajo de la Asamblea Nacional de Weimar en lo que refiere al diseño de un modelo de Estado social y la inclusión de nuevos derechos sociales no ha recibido demasiada atención de la academia porque sigue predominando, en gran medida, una lectura de la Constitución de Weimar como la de una Constitución "fallida". A partir, entonces, de un análisis de las transcripciones de los debates de la Asamblea Nacional de Weimar y en particular de la comisión constitucional, se busca reinterpretar el alcance de las disposiciones diseñadas a la luz del aporte del diputado socialdemócrata Hugo Sinzheimer a la Asamblea. Este análisis permite concluir que el tipo de constitucionalismo social en el que innovó la Asamblea Nacional de Weimar merece ser reinterpretado a partir de la idea de democracia económica, que subyace a las disposiciones principales de la sección económica de la Constitución y que proviene del pensamiento de Sinzheimer sobre el derecho laboral.

Abstract: This article deals with the work of the Weimar National Assembly and in particular Hugo Sinzheimer's one, in order to reinterpret the type of social

Esta investigación fue posible gracias a una beca postdoctoral concedida por el Ministerio de Educación de Argentina y el Servicio Alemán de Intercambio Académico (DAAD) y otra beca otorgada por el Instituto de Historia del Derecho Europeo de Frankfurt am Main, en Alemania, en donde realicé una estancia de investigación entre 2013 y 2016 . Agradezco por los comentarios a distintas versiones de este trabajo a: Thomas Duve, Massimo Meccarelli, Rodolfo Arango, Laura Clérico, Gerd Bender, Peter Collin y Federico de Fazio. 
constitutionalism that was designed in 1919. It is based on the assumption that role of the Weimar National Assembly in regard to the design of a model of social state and the inclusion of new social rights has not received much attention from the academy because a reading of the Constitution as a "failed" one prevails. From a detailed analysis of the transcripts of the debates, the aim is to reinterpret the scope of the social provisions designed, especially, those made by Hugo Sinzheimer. This analysis leads to the conclusion that the type of social constitutionalism in which the Weimar National Assembly innovated could be interpreted on the basis of the idea of economic democracy, which is behind to the main provisions of the economic section of the Constitution and that is connected with Sinzheimer's ideas about labour law.

Palabras Clave: Constitucionalismo social - Constitución de Weimar - Asamblea Nacional de Weimar - Hugo Sinzheimer - Democracia económica

Key Words: Social constitutionalism - Weimar Constitution - Weimar National Assembly - Hugo Sinzheimer - Economic Democracy

\section{INTRODUCCIÓN}

La Constitución de Weimar de 1919, junto con la de Querétaro de 1917 y la Bolchevique de 1918, es considerada como una de las primeras expresiones del movimiento del constitucionalismo social. No sólo ha tenido un rol muy grande como antecedente de la Grundgesetz de Bonn, sino que también ha sido referente en procesos constitucionales similares en otras partes de Europa, Asia y América Latina $^{1}$. En este último caso, incluso es común encontrar la referencia a Weimar en otras asambleas constituyentes que incorporaron derechos sociales ${ }^{2}$ o incluso en la jurisprudencia actual de sus Cortes Constitucionales, especialmente a la hora de interpretar la fórmula "Estado social de derecho", incluida en sus constituciones ${ }^{3}$.

Ahora bien, pese a la influencia -muchas veces más citada que estudiadadel constitucionalismo social de Weimar en España y América Latina, no es mucho lo que se conoce en el ámbito hispanohablante acerca de la teoría constitucional alemana de entreguerras y los debates de la Asamblea Nacional en lo que respecta a las disposiciones de constitucionalismo social ${ }^{4}$. Es conocida la

${ }_{1}$ Para Europa cabe destacar entre otras las constituciones de España (1931), Irlanda (1937) o la de Francia (1946), en el caso de Asía las Constituciones de China (1954) y Taiwán (1947) y para Latinoamérica la Constitución Peruana (1933), de Uruguay (1934), Cuba (1940) y Brasil (1934).

2 Por ejemplo en los debates constituyentes de 1949 en Argentina o de 1934 en Brasil.

${ }^{3}$ Es el caso de algunas sentencias de la Corte Constitucional Colombiana que interpretan el alcance de la formula "Estado social de derecho" incorporada a su Constitución, por ejemplo la T406/92. Cabe aclarar que el concepto "Estado social de derecho" no aparece en ninguna parte de la Constitución de Weimar ni tampoco en los debates de su asamblea, sin embargo, es común que se la identifique como antecedente de esta conceptualización que más tarde Hermann Heller terminaria de definir en 1930. En ese sentido Karl Peter Sommermann, Staatsziele und Staatszielbestimmungen, Mohr, Tübingen, 1997.

${ }_{4}^{4}$ Para el ámbito hispanohablante cabe hacer ciertas salvedades, por ejemplo, respecto de los trabajos de Carlos Miguel Herrera, Les juristes de gauche sous la République de Weimar Les juristes de gauche sous la république de Weimar, Kimé, Paris, 2002; Derecho y socialismo en el pensamiento jurídico. Universidad Externado de Colombia, Bogotá, 2002 y La Constitution de 
particularmente amplia recepción en la academia de habla hispana de las ideas de ciertos juristas de la época de la República (Carl Schmitt, Hans Kelsen, Hermann Heller, en menor medida Rudolf Smend) ${ }^{5}$, pero, incluso en el ámbito de la academia anglosajona donde la teoria constitucional de Weimar viene recibiendo desde hace varios años una atención importante, es muy poco lo que se conoce sobre el debate específico sobre derechos sociales y el constitucionalismo social' ${ }^{6}$.

Algo parecido sucede, como veremos, dentro de la academia alemana, en la que los estudios detallados sobre el trabajo de la Asamblea en materia de Estado social y en particular sobre el aporte de Hugo Sinzheimer, son menos frecuentes que los que se desarrollaron respecto de la Asamblea Constituyente de Bonn ${ }^{7}$. Un tanto más extendida, en cambio, es la literatura referida al trabajo de la Asamblea Nacional de Weimar respecto de otras secciones de la Constitución, como por ejemplo la que se refiere a los poderes de excepción del presidente -en particular el famoso artículo 48-, la relación entre el poder legislativo y ejecutivo o las disposiciones relativas al sistema de partidos o al sistema electoral. Principalmente, lecturas sobre las posibles "fallas" de la Constitución".

Una posible explicación para este fenómeno es el hecho de que lo que siempre ha atraído -y sigue haciéndolo- de la República de Weimar es la pregunta acerca de su caída. En la mayor parte de los trabajos que se abocan al período y en particular a la Constitución de 1919 subyace, de manera expresa o implícita,

Weimar et la pensée juridique française: réceptions, métamorphoses, actualités, Kimé, Paris, 2011 ; o en Argentina Julio Pinto, Carl Schmitt y la reivindicación de la política, Editorial Universitaria del Plata, Buenos Aires, 2000. Para España cabe destacar una serie de nombres que se han dedicado a la República de Weimar desde perspectivas más amplias, como por ejemplo José Luis Villacañas Berlanga, Pablo Lucas Verdú o Sebastián Martín, entre otros.

5 Recepción mediada en parte por las traducciones tempranas de los textos de Schmitt o Heller y por el interés que la teoría del derecho de Kelsen despertó en ciertas academias. Sin embargo, tampoco puede decirse que la recepción haya sido uniforme.

6 Peter Caldwell, Popular sovereignty and the crisis of German Constitutional Law: the theory and the practice of Weimar constitutionalism, Duke University Press, Durham, 1997; Peter Caldwell y William Scheuerman, From Liberal Democracy to fascism: Legal and Political thought in the Weimar Republic, Humanities Press, Boston, 2000; William Scheuerman, Carl Schmitt: The End of Law, Rowman \& Littlefield, Lanham, 1999; David Dyzenhaus, Legality and Legitimacy: Carl Schmitt, Hans Kelsen and Hermann Heller in Weimar, Oxford University Press, Oxford, 1999; David Dyzenhaus, (edit.) Law as Politics: Carl Schmitt's Critique of Liberalism, Duke University Press, Durham, 1998; Arthur Jacobson y Bernhard Schlink, (edit.), Weimar: a Jurisprudence of crisis, University of California Press, Berkeley, 2000; Chantal Mouffe, (edit.), The Challenge of Carl Schmitt, Verso, London, 1999; Ellen Kennedy, Constitutional Failure: Carl Schmitt in Weimar, Duke University Press, Durham, 2004; Leonard Kaplan y Rudi Koshar, (edit.) The Weimar moment: liberalism, political theology and law, Lexington Books, Lanham, 2012; Peter Gordon y John McCormick, (eds.) Weimar Thought: A Contested Legacy, Princeton University Press, Princeton, 2015; entre otros.

7 Christoph Müller, "Hugo Sinzheimer (1875-1945). Selbstorganisation und Selbstverwaltung im Arbeitsrecht", en: Detlef Lehnert (edit.), Vom Linksliberalismus zur Sozialdemokratie. Politische Lebenswege in historischen Richtungskonflikten 1890-1945, Böhlau, Köln, 2015, pp. 146-174; Gerhard Ritter, "Die Entstehung des Räteartikels 165 der Weimarer Reichsverfassung", Historische Zeitschrift, Vol. 258, 1994, pp. 73-112.

8 Christoph Gusy, Weimar. Die wehrlose Republik?: Verfassungsschutzrecht und Verfassungsschutz in der Weimarer Republik, Mohr, Tübingen, 1991. 
el interrogante acerca de cómo pudo acontecer el horror nazi ${ }^{9}$. Así, la visión predominante sobre la Constitución de Weimar sigue siendo, incluso en la academia alemana, la de una Constitución "fallida". Esto también se confirma en los debates que tuvieron lugar en Alemania al momento de la sanción de la Grundgesetz de Bonn: son más las enseñanzas que el derecho constitucional ha extraído de los "errores" de Weimar" ${ }^{10}$ que las que se han recuperado de sus posibles "aciertos" o de su forma particular de constitucionalismo social.

Este trabajo tiene como objetivo indagar acerca del alcance de las ideas sobre el modelo de Estado y de derechos que se dieron en el seno de la Asamblea de 1919 partiendo del supuesto de que esta lectura de la Constitución de Weimar como Constitución fallida ha contribuido a la escasa atención que ha recibido el trabajo de la Asamblea Nacional de Weimar en materia de constitucionalismo social $^{11}$. El problema que nos ocupa es entonces el de las ideas que se debatieron en la Asamblea y no las de sus intérpretes, ya sean estos contemporáneos o posteriores a ese momento. El recorte tampoco obedece a una pretensión de "originalismo", en el sentido de querer identificar las "verdaderas" intenciones de los padres fundadores de la Constitución de 1919, sino al objetivo de rescatar sentidos, ideas y conceptos en torno a la cuestión social que no necesariamente trascendieron luego en la recepción e interpretación de este texto constitucional en Alemania y en otros países. Así, un objetivo que se va más allá de este artículo es el de rastrear qué aspectos de estas ideas pudieron haber sido receptados o traducidos a otros contextos constitucionales ${ }^{12}$.

Este artículo pretende, de esta manera, realizar un aporte al estudio del constitucionalismo social clásico de Weimar desde la perspectiva de la historia de las ideas politicas y jurídicas. Para lograrlo se comenzará con una contextualización del trabajo de la Asamblea Nacional de Weimar identificando primero su lugar en la literatura específica sobre el tema, para luego describir el contexto histórico de su producción legislativa y los detalles sobre su funcionamiento en pleno y en comisiones. A continuación el eje principal serán las ideas de Hugo Sinzheimer, y para ello se detallará su perfil, la propuesta que presenta a la Asamblea en nombre del Partido Socialdemócrata Alemán (SPD) y la

9 Heiko Bollmeyer, Der steinige Weg zur Demokratie. Die Weimarer Nationalversammlung zwischen Kaiserreich und Republik, Campus-Verlag, Frankfurt am Main, 2007.

10 Por ejemplo el abandono de la neutralidad axiológica de la Constitución con el principio de intangibilidad en el inciso 3 del artículo 79, el artículo 21 en su inciso 2, que establece la prohibición de todos aquellos partidos que por sus fines o por el comportamiento de sus adherentes tiendan a desvirtuar o eliminar el régimen fundamental de libertad y democracia, o a poner en peligro la existencia de la República Federal de Alemania, declarándolos inconstitucionales. De la misma manera pueden interpretarse el cambio de una forma semiparlamentarista a una parlamentaria de gobierno, la introducción del voto de censura constructivo, la incorporación de un umbral de exclusión al sistema electoral, la determinación de un estricto control político de las fuerzas armadas por los poderes civiles, entre otros.

11 En este artículos se utilizan las categorías "Estado social" y "derechos sociales" como las variables principales para caracterizar al constitucionalismo social. No obstante, se incluyen dentro de la noción "modelo de Estado" las disposiciones relativas a regulación de la propiedad y la economía.

12 En ese sentido se dirige la investigación actual que vengo realizando sobre la recepción del constitucionalismo social de Weimar en Argentina. En este país, la experiencia de Weimar es especialmente receptada por uno de los artifices de la reforma constitucional argentina de 1949 , Arturo Enrique Sampay. 
interpretación que hace de la misma a partir de las idea de autodeterminación y democracia económica. Finalmente, se presentarán las conclusiones de este análisis en torno al rol de Sinzheimer y de sus ideas sobre la democracia económica a la hora de reinterpretar el legado del constitucionalismo social de Weimar.

\section{EL TRABAJO DE LA ASAMBLEA NACIONAL DE WEIMAR EN LA LITERATURA ESPECIALIZADA}

Como se mencionó, si bien la Constitución de Weimar ha sido objeto de gran interés por parte la academia, no ha pasado lo mismo con el trabajo de la Asamblea Nacional en torno al diseño de un Estado social y la inclusión de derechos sociales en la Constitución. La mayor parte de los estudios sobre la Constitución de Weimar suelen concentrarse en aquello que describen como "falencias" o "defectos" que hicieron posible, junto con otros factores, la llegada de Hitler al poder. Es por eso que por lo general se ocupan de los mecanismos constitucionales que, como el famoso artículo 48, contribuyeron a la crisis institucional que precedió a la caída de la República. Así, la Constitución de Weimar, al menos desde la lectura mayoritaria de historiadores y juristas alemanes, sigue siendo una Constitución fallida, una Constitución con "mala fama"13.

Ahora bien, en lo que refiere a la academia alemana, entre aquellos trabajos que sí se ocupan de la Asamblea Nacional de Weimar podemos encontrar cierta literatura que se aboca a las teorias del Estado presentes en la misma, como por ejemplo la obra de Beyersdorff ${ }^{14}$ o investigaciones posteriores centradas tanto en el pensamiento antidemocrático ${ }^{15}$ como en las ideas democráticas ${ }^{16}$ que predominaban entre los constituyentes. También encontramos algunos estudios sobre la teoria constitucional socialdemócrata ${ }^{17}$.

Entre los análisis e interpretaciones sobre la obra de la Asamblea cabe diferenciar entre las publicaciones de la época de la República que se ocuparon

13 Dieter Grimm, Die Bedeutung der Weimarer Verfassung in der deutschen Verfassungsgechichte, Stiftung Reichspräsident-Friedrich-Ebert-Gedenkstätt, Heildelberg, 1990, p. 3. Algunas interpretaciones alternativas pueden encontrarse por ejemplo en Michael Stolleis, Geschichte des öffentlichen Rechts in Deutschland: Weimarer Republik und Nationalsozialismus, Beck, München, 2002. Stolleis plantea que tal vez en otro ambiente político, más moderado, la Constitución de Weimar hubiera sido viable, ya que no carecía de una buena mecánica constitucional sino en todo caso de una "red de reglas no escritas" que podrian haberla salvado.

14 Hans Beyersdorff, Die Staatstheorien in der verfassunggebenden deutschen nationalversammlung von 1919, Coburger Tageblatt, Coburg, 1928.

15 Kurt Sontheimer, Antidemokratisches Denken in der Weimarer Republik, Dt. Taschenbuch Verl, München, 1962.

16 Kathrin Groh, Demokratische Staatsrechtslehrer in der Weimarer Republik, Mohr, Tübingen, 2010; Tina Pohl, Demokratisches Denken in der Weimarer Nationalversammlung, Dr. Kovač, Hamburg, 2002 y Christoph Gusy (edit.), Demokratisches Denken in der Weimarer Republik, Nomos, Baden-Baden, 2000.

17 Joachim Blau, Sozialdemokratische Staatslehre in der Weimarer Republik, Verlag Arbeiterbewegung und Gesellschaftswissenschaft, Marburg, 1980 y Wolfgang Luthardt, Sozialdemokratische Verfassungstheorie in der Weimarer Republik, Westdeutscher Verlag, Opladen, 1986. 
de la historia "del origen" de la Constitución, como el clásico de Wilhelm Ziegler18 o aquellas que funcionaron por mucho tiempo como clásicos comentarios de la Constitución: las publicaciones de Hugo Preuß ${ }^{19}$ en las que interpreta su propio trabajo, de Gerhard Anschütz ${ }^{20}$, de Walter Jellinek ${ }^{21}$, Hans Nawiasky ${ }^{22}$ o bien los famosos volúmenes del Handbuch des deutschen Staatsrechts editados por Gerhard Anschütz y Richard Thoma ${ }^{23}$. Ya desde la perspectiva de la historia del derecho debemos destacar la reconstrucción que realiza Ernst Rudolf Huber en los últimos tomos de su monumental Deutsche Verfassungsgeschichte seit 1789 [Historia de la Constitución alemana desde 1789] ${ }^{24}$. En el mismo sentido, cabe mencionar las más recientes obras de Willibalt Apelt ${ }^{25}$, Karl Dietrich Bracher ${ }^{26}$, Christoph Gusy ${ }^{27}$ y Heiko Bollmeyer ${ }^{28}$.

Ahora bien, específicamente sobre el rol de la Asamblea en la redacción de la segunda parte de la Constitución (la referida a derechos y deberes de los alemanes), se destacan la obra de Karsten Bendix ${ }^{29}$, Friedhelm Köster ${ }^{30}$ y Walter Pauly $^{31}$. Los tres analizan los debates de la Asamblea y de la comisión constitucional en clave con las ideas que dieron origen a los derechos incorporados. Sin embargo, estos trabajos no se dedican de manera específica al constitucionalismo social, sino que se interesan principalmente por la categoría de derechos fundamentales. Quien si se concentra específicamente en esta

18 Wilhelm Ziegler, Die Deutsche Nationalversammlung 1919-20 und ihr Verfassungswerk, Zentralverlag, Berlin, 1932.

19 Hugo Preuß, Um die Reichsverfassung von Weimar, Mosse, Berlin, 1924; Hugo Preuß, Staat, Recht und Freiheit. Aus 40 Jahren deutscher Politik und Geschichte, Mohr, Tübingen, 1926 y Hugo Preuß, Deutschlands republikanische Reichsverfassung, Neuer Staat, Berlin, 1923.

20 Gerhard Anschütz, Die Verfassung des Deutschen Reiches vom 11.August 1919, Stilke, Berlin, 1933 y Gerhard Anschütz, Drei Leitgedanken der Weimarer Reichsverfassung. Mohr, Tübingen, 1923.

21 Walter Jellinek, "Revolution und Reichsverfassung. Bericht über die Zeit vom 9. November 1918-31. Dezember 1919”, Jahrbuch des öffentlichen Rechts, N9, 1920, pp. 1-128.

22 Hans Nawiasky, Die Grundgedanken der Reichsverfassung, Duncker \& Humblot München, 1920.

23 Gerhard Anschütz y Richard Thoma (edit.), Handbuch des Deutschen Staatsrechts, Mohr, Tübingen, 1932.

24 Ernst Rudolf Huber, Deutsche Verfassungsgeschichte seit 1789, T. 6 y 7, Kohlhammer Verlag, Stuttgart, 1978.

25 Willibalt Apelt, Geschichte der Weimarer Verfassung, Biederstein, München, 1946.

26 Karl Dietrich Bracher, Die Entstehung der Weimarer Verfassung, Niedersächsische Landeszentrale für Politische Bildung, Hannover, 1963.

27 Christoph Gusy, "Die Entstehung der Weimarer Reichsverfassung”, Juristenzeitung, 49 (15), 1994, pp. 753-763; Christoph Gusy, Die Weimarer Reichsverfassung, Mohr, Tübingen, 1997.

28 Heiko Bollmeyer, Der steinige Weg zur Demokratie. Die Weimarer Nationalversammlung zwischen Kaiserreich und Republik, Campus-Verlag, Frankfurt am Main, 2007.

29 Karsten Bendix, Die Arbeit des Verfassungsausschusses: Achter Ausschuss der verfassungsgebenden Nationalversammlung von Weimar. Peter Lang, Frankfurt am Main, 2002.

30 Friedhelm Köster, Entstehungsgeschichte der Grundrechtsbestimmungen des zweiten Hauptteils der Weimarer Reichsverfassung, Cuvillier Verlag, Göttingen, 2003.

31 Walter Pauly, Grundrechtslaboratorium Weimar. Zur Entstehung des zweiten Hauptteils der Reichsverfassung vom 14. August 1919, Mohr, Tübingen, 2004. 
cuestión es Friedrich Völtzer ${ }^{32}$, en una disertación sobre la idea de Estado social en la Constitución de Weimar. Allí el autor busca los rastros de un "Sozialstaatsgedanke" (pensamiento del Estado social) en los debates constituyentes y los analiza a la luz de las concepciones de Estado social presentes en la teoría política alemana. Más allá de las obras mencionadas encontramos algunas pocas investigaciones que, si bien tratan sobre el trabajo de la Asamblea en la redacción de la segunda parte de la Constitución y en particular en el diseño de un Estado social, se abocan específicamente a alguna cuestión particular, como por ejemplo a la idea de Consejos o "Rätesgedanke" 33 .

En sintesis, lo que una revisión de la bibliografia sobre el tema permite comprobar es que el trabajo de la Asamblea Nacional de Weimar en materia de Estado social y derechos sociales no ha recibido tanta atención por parte de la academia. Así, de manera explícita o implícita, la lectura de la Constitución de Weimar como una Constitución "fallida" parece haber contribuido a que sea bastante poco lo que se conoce, especialmente fuera de la academia germana, acerca de las particularidades del constitucionalismo social diseñado en 1919. A examinar algunos de estos aspectos menos trabajados se orientan las páginas que siguen.

\section{LA ASAMBLEA NACIONAL DE WEIMAR EN ACCIÓN}

La advertencia de que un proceso constituyente no puede ser entendido sin recurrir al contexto histórico es insoslayable para el caso de Weimar. Es imposible interpretar correctamente la obra de la Asamblea Nacional de Weimar (oficialmente la Verfassunggebende Deutsche Nationalversammlung), a sus protagonistas o al texto finalmente sancionado, si perdemos de vista los sucesos que desencadenaron el nacimiento de la República y la opción por un gobierno a cargo del SPD. En otras palabras, la Constitución de Weimar -y sus ideas- sólo pueden ser interpretadas a la luz de la derrota alemana en la primera guerra mundial y sus consecuencias para la organización del país.

La República de Weimar era la primera experiencia alemana de democracia, salvo por un breve período en 1848, pero fue menos un proceso ganado por un sector social excluido de la participación política que el resultado de una derrota bélica. Los hechos de 1918 dejaron la vía libre para que el partido socialdemócrata se hiciera cargo del poder y tuviera la oportunidad de diseñar las instituciones de esa naciente democracia. Pero la consagración constitucional de un modelo de Estado social tenía sus antecedentes en el período anterior. La legislación ya había avanzado mucho en esa dirección ${ }^{34}$ y de igual manera a principios de siglo ya se había planteado en Alemania, como en otras partes de

32 Friedrich Völtzer, Der Sozialstaatsgedanke in der Weimarer Reichsverfassung, Peter Lang, Frankfurt am Main, 1992.

33 Karl Albrecht, Hugo Sinzheimer in der Weimarer Nationalversammlung: Sein Beitrag zum wirtschaftlichen Rätesystem und zu den arbeits- und wirtschaftsrechtlichen Grundrechten der Reichsverfassung. Dissertation. Universität Frankfurt am Main, Frankfurt am Main, 1970; Gerhard Ritter, “Die Entstehung des Räteartikels 165 der Weimarer Reichsverfassung”, op. cit.

34 No olvidemos que Alemania ya tenía un seguro universal de desempleo y numerosas leyes para paliar las consecuencias sociales de la guerra. Para más detalle sobre el tema ver Michael Stolleis, Origins of the German Welfare State. Social Policy in Germany to 1945, Springen, Heidelberg, 2013. 
Europa, un importante debate en las ciencias jurídicas en torno a la necesidad de incorporar la cuestión social al derecho común ${ }^{35}$. Sin embargo, es cierto que hasta entonces nunca se había planteado la inclusión de estas cuestiones a un nivel constitucional.

Ahora bien, lo que en un principio podría haber sido una auténtica alternativa socialista -que incluyó la discusión sobre la posibilidad de constituir consejos al estilo bolchevique y se experimentó de manera fallida en Baviera-36 terminó convirtiéndose en una salida moderada que intentaba alejarse de las alternativas más extremas ${ }^{37}$. La misma convocatoria a una Asamblea Constituyente fue resultado de esta opción. De igual manera lo fue la elección de Hugo Preuß -entonces ministro del interior- para el encargo de la redacción de un borrador oficial. El solo hecho de que se le encomendara redactar un proyecto de Constitución a un liberal, muestra lo endeble del papel de la socialdemocracia en el poder. Nunca se barajó el nombre de un socialdemócrata y no fue -como veremos- porque no contaran con nombres a la altura de tal tarea. La fuerza política que tenía el poder en sus manos renunció, desde un principio, a establecer un programa constitucional propio y le regaló esa oportunidad a la burguesía liberal del Deutsche Demokratischen Partei (DDP) [partido democrático alemán].

Preuß dirigió una serie de reuniones previas a las sesiones de la Asamblea de las que participó, entre otros, Max Weber. Sin embargo, en lo que respecta al diseño del primer constitucionalismo social alemán ni Preuß ni Weber jugarían un rol importante ${ }^{38}$. En esas reuniones $-\mathrm{y}$ en los borradores que surgieron como consecuencia- no se discutieron esos aspectos ${ }^{39}$ sino cuestiones relativas a la

$35 \mathrm{Me}$ refiero específicamente para Alemania a las críticas realizadas por Otto von Gierke en Entwurf eines bürgerlichen Gesetzbuches und das Deutsche Recht, Dunker \& Humblot, Leipzig, 1888 y Die soziale Aufgabe des Privatrechts, Springer, Berlin, 1889 y también a la obra de Anton Menger, Das bürgerliche Recht und die besitzlosen Volksklassen. Eine Kritik des Entwurfs eines Bürgerlichen Gesetzbuches für das Deutsche Reich, H. Laupp, Tübingen, 1890. Ambos autores ya habian realizado un análisis crítico al proyecto de Código Civil Alemán. Estas obras formaron parte del horizonte de sentido desde el cual la Asamblea de Weimar trabajó.

36 La cuestión de los consejos es central para comprender gran parte de las disposiciones de la sección económica de la Constitución de 1919. El así llamado "Rätebewegung" (movimiento de consejos) fue muy importante en la Alemania de postguerra. Ante el planteamiento por parte de los sectores más radicales de conformar una democracia fundada en los consejos, se celebró en Berlín en 1918 un Congreso General de los Consejos de Trabajadores y Soldados en el que se decidió apoyar la convocatoria a una Asamblea Constituyente en lugar de consagrar la dictadura de los consejos al estilo bolchevique. El fantasma del bolchevismo estaba demasiado presente para no influir en la delimitación de las funciones de los consejos. Sobre el tema ver entre otros Dähn, Horst, Rätedemokratische Modelle. Studien zur Rätediskussion in Deutschland 1918-1919, Anton Hain, Meisenheim am Glan, 1975.

37 Me refiero, entre otros, a los asesinatos de Karl Liebknecht y Rosa Luxemburgo.

38 Gran parte de la literatura ha destacado la relevancia de Weber para el diseño del sistema semipresidencialista de Weimar. Ver entre otros Wolfgang Mommsen, Max Weber und die deutsche Politik: 1890-1920, Mohr, Tübingen, 1959.

39 Sí lo incluía uno de los proyectos privados que fueron presentados, el del teórico del Estado Johannes Viktor Bredt, que contemplaba una sección de derechos fundamentales. E1 proyecto preveía también la creación de tribunales laborales, el derecho de asociación, el derecho al trabajo, socialización y obligaciones sociales de la propiedad y derecho a la vivienda. Este proyecto, puede pensarse, no influyó en el de Preuß, sin embargo sí podria haber sido leído en el 
forma de gobierno republicana, parlamentaria, semipresidencialista y a la cuestión federal. En efecto, el borrador ofrecido por Preuß respondia exclusivamente a un modelo constitucional liberal. En su proyecto prevalecía la idea de un "minimalismo constitucionalista" que buscaba a toda costa evitar los problemas que había tenido la Asamblea Constituyente de Paulskirche en 1848, durante la cual los largos debates a la hora de incorporar un catálogo de derechos colaboraron con el fracaso de la revolución ${ }^{40}$. Esto se comprueba en el análisis de los debates de la Asamblea, porque en muchas ocasiones Preuß rogó a los diputados constituyentes que desistieran de discutir sobre derechos para que se apresuraran en sus deliberaciones y no comprometieran la suerte del proceso constituyente.

La Asamblea Nacional fue elegida el 19 de enero de 1919 en elecciones que por primera vez incluyeron a las mujeres y utilizaron un sistema electoral proporcional. Se componía por 423 diputados y diputadas de los cuales la mayor parte eran socialdemócratas (165), algunos cuantos se identificaban como socialdemócratas independientes (22), y el resto o bien formaban parte de lo que sería la coalición de Weimar: representantes del partido católico del Zentrum (89) y del DDP (74) o de otros partidos de ideología de derecha como el Deutsche Volkspartei (DVP) [Partido Popular Alemán] (22) o el Deutsche Nationalen Volkspartei (DNVP) [Partido Nacional del Pueblo Alemán] (42) u otros partidos varios (9).

El 6 de febrero de 1919 se reunieron por primera vez en la Ciudad de Weimar $^{41}$. La Asamblea aprobó el texto final de la Constitución el 29 y 30 de julio por 262 votos, con 75 en contra y una abstención. El presidente Ebert la promulgó el 11 de agosto de 1919 y el 14 de agosto de 1919 la Constitución fue publicada y entró en vigor. Durante la mayor parte de esos seis meses que duraron las deliberaciones la Asamblea tuvo que ocuparse de resolver cuestiones de coyuntura politica que inevitablemente quitaron tiempo al debate constitucional. En paralelo con las deliberaciones que tenian lugar en la tranquila ciudad de Weimar, el país batallaba contra una severa crisis económica, conflicto social, huelgas generales y además lidiaba con la firma del tratado de Versalles. De esta manera, el trabajo de la Asamblea estuvo inevitablemente signado por estos acontecimientos. $\mathrm{Ni}$ siquiera su "exilio" en Weimar pudo aislarla de la vorágine económica, politica y social en la que el país estaba sumergido.

En cuanto a su estructura, la Asamblea Nacional decidió crear comisiones de trabajo con el objetivo de trabajar en las criticas al borrador elaborado por Preuß. Hubo una en particular que fue determinante en el diseño de la segunda parte de la Constitución: la "octava", conocida también como la "comisión

seno de la comisión constitucional. Ver Friedrich Völtzer, Der Sozialstaatsgedanke in der Weimarer Reichsverfassung, op. cit.

40 Michael Stolleis, Geschichte des öffentlichen Rechts in Deutschland: Weimarer Republik und Nationalsozialismus, op. cit.

41 Los motivos de esta elección han sido objeto de distintas teorías. La más recurrente es que se buscó un lugar estratégicamente más fácil de defender que Berlin. También se ha dicho que se intentó con esta elección ligar el presente de Alemania a la tradición cultural de Weimar. Ver Hagen Schulze, Weimar. Deutschland 1917-1933, Siedler, Berlin, 1998 y

Horst Möller, Die Weimarer Republik. Eine unvollendete Demokratie, DTV, München, 2004. 
constitucional". Comenzaron su trabajo el 4 de marzo de 1919, al final de la primera lectura y sesionaron durante poco más de tres meses. Estaba compuesta por veintiocho delegados de los diferentes partidos ${ }^{42}$. En esas deliberaciones se decidió crear una subcomisión que deliberó durante ocho dias durante el mes de mayo. El trabajo de esta última no fue determinante a la hora de incorporar nuevas disposiciones al proyecto pero sí al momento de sistematizar el borrador final $^{43}$. Lamentablemente no hay protocolos de sus deliberaciones porque sesionaron en privado. Lo que se conoce de esas deliberaciones se logró reconstruir a partir de documentos y otros papeles de sus integrantes ${ }^{44}$.

Se ha dicho que el ámbito donde más libremente operaron los partidos politicos en la Asamblea fue precisamente el de la parte dogmática de la Constitución. Es decir, en lo referido a los derechos y deberes. En ese punto no había tantos intereses particulares del Reich o de ciertas burocracias estatales ${ }^{45}$ porque, como se destacó, no era un problema que hubiera sido incorporado al primer borrador por Preuß y en todo caso terminó "colándose" durante las sesiones posteriores. En otras disposiciones, como las referidas a la cuestión federal, la interferencia del gobierno o de los representantes de los Länder (Estados Federados) en lo que sería la redacción definitiva fue muy superior.

El proyecto oficial -redactado por Preuß- no incluía ningún catálogo de derechos ${ }^{46}$ como tampoco disposiciones con contenido social. Estos elementos fueron incorporados con posterioridad a la primera lectura en pleno de la Asamblea, durante la cual se plantearon fuertes criticas al proyecto oficial por su escaso contenido social. Fue entonces al final de esa primera lectura que se decidió derivar el proyecto a una comisión constitucional para revisar estas críticas y trabajar sobre cambios ${ }^{47}$. La comisión constitucional comenzó a sesionar enseguida y fue durante esas deliberaciones que se presentó una

4211 del SPD, 5 del DDP, 6 del Zentrum, 3 del Deutschnationale Volkspartei (DNVP) y uno de los socialdemócratas independientes (USPD). La transcripción de los debates de la comisión fueron posteriormente incluidos en la publicación de los debates de la Asamblea pero siguen siendo hoy una de las fuentes menos consultadas. Ver Karsten Bendix, Die Arbeit des Verfassungsausschusses: Achter Ausschuss der verfassungsgebenden Nationalversammlung von Weimar, op. cit.

43 La subcomisión estuvo liderada por el diputado del Zentrum católico, el historiador del derecho Konrad Beyerle. Sobre él se ha destacado que es necesario ver su trabajo no en relación con su filiación partidaria sino con su compromiso con la comisión. Ver Friedrich Völtzer, Der Sozialstaatsgedanke in der Weimarer Reichsverfassung, op. cit. Su aporte mas sustancial fue el de sistematizar las principales propuestas en un solo catálogo.

44 Al respecto Friedrich Völtzer destaca que en el seno de esta comisión se llegó a plantear la cuestión de la operatividad directa de los derechos sociales recién incorporados. De hecho el texto redactado por la subcomisión tenía una cláusula general que habilitaba la invocación constitucional ante la violación de un derecho. Algo absolutamente adelantado para la época. Esta cláusula, sin embargo, fue excluida en las siguientes lecturas de la comisión. Ver Friedrich Völtzer, Der Sozialstaatsgedanke in der Weimarer Reichsverfassung, op. cit.

45 Hans Mommsen, The Rise and Fall of Weimar Democracy, University of North Carolina Press Chapel Hill, 1996.

46 Sin embargo, se mencionaban algunos derechos de corte liberal.

47 En esos debates se planteó también la necesidad de una ley de socialización, ley que terminó sancionándose el 23 de marzo de 1919 con el objetivo de bajar la agitación de los más radicales. Ver Ernst Rudolf Huber, Deutsche Verfassungsgeschichte seit 1789, T. 6, op. cit. 
primera propuesta que cambió la suerte del texto constitucional: la de incorporar a la Constitución un catálogo de derechos fundamentales.

Esta idea provino de Friedrich Naumann, quien no era jurista sino un pastor protestante elegido por el partido $\mathrm{DDP}^{48}$. Su propuesta podria ser descripta como una serie de regulaciones sin forma jurídica dirigidas a describir un acuerdo entre capitalismo y socialismo (Verständigungsfriede) ${ }^{49}$. Naumann entendia que los derechos naturales contenidos en el liberalismo clásico deberían expandirse hasta incluir derechos sociales básicos consistentes con los requerimientos de las modernas sociedades industriales. Partía de la idea de que los derechos debían ser "entendibles" para el pueblo y que por eso no era necesario preocuparse por su forma jurídica. Además de derechos incluía una lista de "obligaciones" que entendia, eran correlativas a los primeros. Para los juristas que formaban parte de la comisión, la propuesta de Naumann, a quien consideraban un "outsider"50 era totalmente extravagante. Sin embargo, sus ideas tuvieron un eco decisivo en el auditorio, ya que a partir de allí se comenzó a debatir sobre la importancia de sumar a la constitución minimalista de Preu $\beta$ un catálogo de derechos.

Naumann fundamentó su propuesta a la comisión en un discurso el 31 de marzo de 1919. Allí habló del cambio en el concepto de Estado (Staatsbegriff) que la revolución de 1918 había traído a Alemania y de la necesidad de que ese nuevo concepto fuera incorporado a la Constitución. Esta transformación, entendía, impactaba también en la esfera económica ya que urgía comprender que la economía de todos debía prevalecer sobre la privada: "Volkswirtschaft steht über Privatwirtschaft". Todo esto, justificaba, se derivaba del contexto histórico particular de Alemania en 1919. El país se encontraba entre dos modelos: el norteamericano-europeo occidental vs. el soviético. Incorporar un catálogo de derechos a la Constitución implicaba, desde su punto de vista, la elección por el primer modelo. Sin embargo, el sistema soviético podía funcionar como un referente, porque así como la Constitución soviética había dado poder a la clase trabajadora, los derechos incorporados a la Constitución de Weimar debían ser "reales", debían "llevar a un cambio en el concepto de Estado" y no quedarse en meras palabras ${ }^{51}$.

Además de esta propuesta se presentaron también en la comisión las del SPD, el DNVP y algunas otras del Zentrum y el DVP. Sin embargo, la que mayor impacto tendría en el articulado final sería la del partido socialdemócrata, y en

48 Partido que él mismo había fundado junto con Theodor Wolff y Hugo Preuß. Con anterioridad a su participación en la Asamblea se había desempeñado politicamente cerca de las clases trabajadoras y era muy cercano a Max Weber. Ver Andreas Lindt, Friedrich Naumann und Max Weber. Theologie und Soziologie im wilhelminischen Deutschland, TEH, München, 1973 y Peter Theiner, Sozialer Liberalismus und deutsche Weltpolitik: Friedrich Naumann im Wilhelmischen Deutschland (1860-1919), Nomos Verlag, Baden-Baden, 1983.

49 Este tipo de pensamiento liberal impregnado de responsabilidad social era tipico entre los llamados "Kathedersozialisten" o socialistas de cátedra Éstos eran profesores universitarios e historiadores que esperaban reorientar la politica social y económica alemana a partir de su investigación. Ver entre otros Fritz Völkerling, Der deutsche Kathedersozialismus, Verlag die Wirtschaft, Berlin, 1959.

50 Ernst Rudolf Huber, Deutsche Verfassungsgeschichte seit 1789, T. 6 y 7., op. cit.

51 Stenographische Berichte über die Verhandlungen der Verfassunggebenden Deutschen Nationalversammlung, T. 336, p. 180. 
particular, las disposiciones que redactara Hugo Sinzheimer. A ellas nos dedicaremos a continuación.

\section{La figura de Hugo Sinzheimer en tiempos de la República}

El partido socialdemócrata alemán contaba con 163 diputados en la Asamblea Nacional pero muy pocos de ellos eran abogados. Sinzheimer no sólo era uno de ellos sino que era una de las mentes más brillantes del debate. Constituía un verdadero "jurista universal"52: eximio docente, académico, abogado del foro y en el ámbito público, un notable orador. Sus ideas le dieron forma y contenido al derecho laboral alemán naciente ${ }^{53}$ por eso se lo considera el padre de esta disciplina en Alemania y en particular, el creador de la noción de Tarifvertrag (convenio colectivo). Sinzheimer habia nacido en el seno de una familia judia de comerciantes en 1875 en la ciudad de Worms, cerca de Frankfurt am Main ${ }^{54}$. Estudió derecho y economía en Múnich, Berlín, Freiburg, Marburg y Halle y tuvo la oportunidad de asistir a las clases de Lujo Brentano, quien influyó fuertemente en su obra, al igual que lo hicieran Otto von Gierke, Karl Renner, Karl Marx y Eugen Ehrlich, entre otros ${ }^{55}$.

Después de defender su disertación en la Universidad de Heidelberg sobre el tema Lohn und Aufrechnung (Salario y compensación) se estableció en 1903 en Frankfurt donde ejerció la abogacía. En un primer momento se desempeñó en derecho penal, defendiendo sindicatos y trabajadores perseguidos en tiempos de Bismarck. Ya durante la República se dedicó de lleno al derecho laboral, asesorando tanto a trabajadores individuales como al sindicato de los Trabajadores del Metal. Incluso llegó a representar a la Allgemeine Deutsche Gewerkschaftsbund-ADGB- (Federación Alemana de Sindicatos) en el Tribunal Estatal de Leipzig56. Esta experiencia de cercanía con el movimiento de los trabajadores sería un rasgo común de los primeros juristas vinculados al

52 Karl Albrecht, Hugo Sinzheimer in der Weimarer Nationalversammlung: Sein Beitrag zum wirtschaftlichen Rätesystem und zu den arbeits- und wirtschaftsrechtlichen Grundrechten der Reichsverfassung, op. cit.

53 Otto Kahn-Freund, Labour Law and Politics in the Weimar Republic, Basil Blackwell Publisher Oxford, 1981.

54 Para una biografia de Sinzheimer ver Ernst Fraenkel, "Hugo Sinzheimer", Juristenzeitung, $\mathrm{N}^{\circ} 15$, 1958, pp. 457-461; Susanne Knorre, Soziale Selbstbestimmung und individuelle Verantwortung: Hugo Sinzheimer (1875-1945). Eine politische Biographie. Peter Lang, Frankfurt am Main, 1991; Hans Peter Benöhr, “Hugo Sinzheimer (1875-1945)", en Bernhard Diestelkamp y Michael Stolleis (edit.) Juristen an der Universität Frankfurt am Main, Nomos, Baden-Baden, 1989, pp. 67-83; Sandro Blanke, Soziales Recht oder kollektive Privatautonomie? Hugo Sinzheimer im Kontext nach 1900, Mohr, Tübingen, 2005 y Abraham de Wolf, Hugo Sinzheimer und das jüdische Gesetzesdenken im deutschen Arbeitsrecht, Hentrich \& Hentrich Verlag, Berlin, 2015. La biografia más documentada es la escrita por un profesor japonés: Keiji Kubo, Hugo Sinzheimer - Vater des deutschen Arbeitsrechts - Eine Biographie, Bund Verlag, Köln, 1999. En relación a su aporte al derecho laboral alemán ver Ulrich Zachert, "Hugo Sinzheimer: praktischer Wissenschaftler und Pionier des modernen Arbeitsrechts", Recht der Arbeit (RdA), 54, 2001, pp.104-109. .

55 Como veremos, sin embargo, una de las influencias más fuertes será la de Gierke, con cuyo pensamiento estaba fascinado. Ver Christoph Müller, "Hugo Sinzheimer (1875-1945). Selbstorganisation und Selbstverwaltung im Arbeitsrecht", op. cit. Sobre la recepción de Gierke en Sinzheimer ver Malowitz, 2003.

56 Abraham de Wolf, Hugo Sinzheimer und das jüdische Gesetzesdenken im deutschen Arbeitsrecht, op. cit. 
naciente derecho laboral. Si bien provenian en gran parte del derecho privado, tenían una visión muy diferente en relación al análisis de las decisiones jurídicas, la interpretación de la relación laboral, las reglas del mercado y la intervención estatal 57 .

Ya desde principios de siglo, Sinzheimer publicó numerosas obras que son todavia hoy referencia ineludible del derecho laboral alemán y del derecho colectivo en general: Der korporative Arbeitsnormenvertrag (El contrato laboral corporativo) publicada en dos tomos en 1907 y 1908, o ya de tiempos de la República Die Grundzüge des Arbeitsrechts (Principios básicos del derecho del trabajo), obra que influyó fuertemente en jóvenes abogados laboralistas como Kahn Freund (McGaughey y Kahn-Freund, 2016). En 1916 publicó Ein Arbeitstarifgesetz. Die Idee der sozialen Selbstbestimmung in Recht (Una ley de Convenios Colectivos. La idea de autodeterminación social en el derecho) que sirvió de base para la ley sancionada sobre el tema en 1923 (Tarifvertragsordnung). En 1912 fundó, junto con Karl Flesch y Philipp Lotmar un comité para el estudio sistemático de la legislación laboral. Desde 1913 trabajó junto con el liberal Heinz Potthoff en la primera revista sobre derecho laboral que llevó ese nombre.

Asimismo, mientras que gran parte de los académicos y profesores de la época se veían a sí mismos como genuinamente "apoliticos", ese nunca fue el caso de Sinzheimer ${ }^{58}$. Si bien en un primer momento, al igual que Hugo Preu $\beta$, se encontró cerca del liberalismo de izquierda, a diferencia de éste se afilió al SPD en 1914 y permaneció desde entonces vinculado al partido. En 1917 fue elegido diputado por ese partido para la legislatura de la ciudad de Frankfurt, donde ejerció durante los días de la revolución de noviembre como presidente provisional de la policía. El punto máximo de su carrera política llegaría el 19 de enero de 1919 al ser elegido para representar al SPD en la Asamblea Nacional de Weimar. Después de esa experiencia, empero, no volvió a ocupar cargos públicos. Llegó a estar nominado por la cúpula del partido para el cargo de Ministro de Trabajo pero su propuesta legislativa para responsabilizar a los militares por la extensión injustificada de la guerra le valió varios enemigos y lo dejó fuera de juego ${ }^{59}$.

Tal vez decepcionado por este episodio Sinzheimer se abocó desde entonces de lleno a la academia. De 1920 y hasta 1930 ejerció como Honorarprofessor (profesor honorario) de derecho del trabajo en la Universidad de Frankfurt ${ }^{60}$. Sus clases eran muy populares entre los estudiantes, entre quienes figuraban los que fueron luego grandes figuras del derecho alemán como Ernst Fraenkel, Otto Kahn Freund, Franz Neumann, Hans Morgenthau y Carlo Schmid, entre otros. Como hicieran otros juristas socialistas de la época se comprometió con la educación de

57 Michael Stolleis, Geschichte des öffentlichen Rechts in Deutschland: Weimarer Republik und Nationalsozialismus, op. cit.

58 Michael Stolleis, Geschichte des öffentlichen Rechts in Deutschland: Weimarer Republik und Nationalsozialismus, op. cit.

59 Abraham de Wolf, Hugo Sinzheimer und das jüdische Gesetzesdenken im deutschen Arbeitsrecht, op. cit.

60 El cargo de profesor, como a tantos otros juristas judios de la época, le llegó tarde a Sinzheimer. Ver Helmut Heinrichs, et. al. (edit.), Deutsche Juristen jüdischer Herkunft. Beck, München, 1993. 
los trabajadores y cofundó en 1921 la Akademie der Arbeit (Academia del Trabajo), un centro de formación académica para los trabajadores que aún hoy existe. Finalmente, también fue editor asociado de la revista "Die Justiz", órgano de la pequeña Vereinigung des Republikanischen Richterbundes (Asociación de jueces y juristas republicanos), en la que publicó hasta 1931 numerosas e interesantes crónicas como observador político de su tiempo.

Con la llegada de Hitler al poder y por su doble condición de socialista y judio, los días de Sinzheimer en Frankfurt estaban contados. Tras ser apresado un par de veces en Alemania se exilió en Holanda, en donde le ofrecieron la cátedra de Sociología del Derecho. Su discurso de toma de posesión del cargo en la Universidad de Amsterdam se tituló Das Problem des Menschen im Recht [E] problema del ser humano en el Derecho] trabajo de fuerte impronta humanista que fuera más tarde incluido en sus obras completas. En 1940, tras la invasión nazi a Holanda, fue encarcelado nuevamente pero logró evitar la deportación viviendo por varios años oculto en la casa de sus amigos. Falleció a causa de los males que esas condiciones de vida le ocasionaron, al poco tiempo de que fuera liberada Holanda y un día antes de la que iba a ser su clase de despedida antes de asumir como profesor emérito en la Universidad de Amsterdam, un 16 de septiembre de 1945 .

\section{La Propuesta Socialdemócrata para un Estado Social}

Sinzheimer no era originalmente miembro de la comisión constitucional que se formó tras la primera lectura sino que fue llamado a ella una vez que ésta empezó a sesionar. Era claro para los representantes de la socialdemocracia en la Asamblea que él era el experto por excelencia en materia de Sozialpolitik (política social) ${ }^{61}$. Así es que, una vez en la comisión, presentó una propuesta en conjunto con el diputado Max Quarck que intentaba ir más allá de la de Naumann62. En ella buscaba dar una formulación jurídica a las ideas planteadas por el pastor pero sin descuidar que fueran accesibles al pueblo.

La propuesta constaba de quince artículos, de los cuales cuatro se referían explícitamente al contenido social y económico de la Constitución. Además de prever el derecho a la educación de los trabajadores y a su participación en el desarrollo artístico y espiritual de la nación, establecía en su artículo 39, la necesidad de que el Estado controlara que la vida económica individual no tendiera a la ganancia privada sino a la construcción de la dignidad humana. En el mismo artículo preveía que en nombre del interés económico general (das wirtschaftliche Gesamtinteresse) el Estado podía socializar propiedad privada, participar en empresas, oponerse a ciertas decisiones económicas de asociaciones (Verbände) y se establecía la base de lo que luego se convertiría en el famoso artículo 165: la obligación del Estado de crear órganos autónomos (Selbstverwaltungskörper) en los que trabajadores y empleadores tuvieran igual poder de participación y decisión. Además, la propuesta incluía un artículo que garantizaba la protección de la fuerza de trabajo (artículo 40), otro que preveía el

61 Christoph Müller, "Hugo Sinzheimer (1875-1945). Selbstorganisation und Selbstverwaltung im Arbeitsrecht", op. cit.

62 La propuesta puede consultarse en Stenographische Berichte...T. 336, p. 178 y ss. 
derecho a un seguro por desempleo (artículo 41) y una previsión acerca de licencias sin goce de sueldo (artículo 42).

Sinzheimer justificó en la misma sesión que Naumann su propuesta63. Allí afirmó la necesidad de darles a estas ideas sociales una forma jurídica -en contraposición a la concepción de Naumann- y propuso establecer que los nuevos derechos no pudieran ser modificados salvo por mayoría agravada del parlamento. Asimismo dio a entender la que sería la postura oficial del partido sobre su operatividad directa: estos derechos constituirian directrices (Richtlinien) de las leyes comunes y determinarian los objetivos del Estado. Dejando, de esta manera, claro que no se estaba buscando que tuvieran un efecto directo, sino que deberían ser reglamentados luego por el poder legislativo.

Si comparamos esta propuesta con el proyecto oficial por un lado y la versión final del texto constitucional por otro, no podemos dejar de advertir la importancia de este documento para la historia de la Constitución social de Weimar64. Los puntos más decisivos con respecto al Estado social y a los derechos sociales ya estaban incluidos allí. En las sesiones posteriores sólo se harian pequeñas modificaciones que no cambiarian en lo sustancial la propuesta elaborada por Sinzheimer. Su aporte como jurista fue fundamental para la redacción de estos artículos, porque si bien algunas de estas ideas eran compartidas por otros integrantes de la Asamblea él supo formularlas con forma jurídica y como se verá más adelante, también pudo fundamentarlas en un todo sistemático.

Esto vale en particular para el artículo que recibió un tratamiento especial y que luego fuera ampliado y rediseñado por el mismo Sinzheimer: el que terminaría siendo el artículo 165 de la Constitución o Räteartikel (artículo de los consejos). La cuestión de los consejos era algo que venía de la experiencia revolucionaria de $1918^{65}$. Existía una fuerte demanda por parte del movimiento obrero para que este asunto fuera incorporado a la Constitución. Pero esa no era la posición oficial del gobierno. En efecto, en un artículo publicado en el Berliner Tageblatt del 26 de febrero de 1919 el gabinete aclaraba que no era su intención incluir ningún tipo de sistema de consejos66. A los pocos días tendría que desdecirse. Arrancando por la cuenca del Ruhr se empezó a hacer sentir en Alemania una ola de huelgas que luego se fue expandiendo a Berlín y otras regiones. La presión de la clase obrera para que el tema de los consejos fuera tenido en cuenta por la Asamblea era cada vez más fuerte ${ }^{67}$.

63 Stenographische Berichte...T.336, p. 182 y ss.

${ }^{64}$ En ese sentido Friedrich Völtzer, Der Sozialstaatsgedanke in der Weimarer Reichsverfassung, op. cit.

65 Sobre el tema ver Wilhelm Römer, Die Entwickelung des Rätegedankens in Deutschland, Ebering, Berlin, 1921 y Dähn, Horst, Rätedemokratische Modelle. Studien zur Rätediskussion in Deutschland 1918-1919, op. cit.

66 Gerhard Ritter, “Die Entstehung des Räteartikels 165 der Weimarer Reichsverfassung”, op. cit.

67 La violencia vivida en esos meses en Berlín fue mucho mayor a la sucedida en San Petersburgo en 1917, era lógico que temieran tanto a los consejos. Ver Karl Albrecht, Hugo Sinzheimer in der Weimarer Nationalversammlung: Sein Beitrag zum wirtschaftlichen Rätesystem und zu den arbeits- und wirtschaftsrechtlichen Grundrechten der Reichsverfassung, op. cit. 
De esta manera, la idea de incorporar a la Constitución algún tipo de normativa relativa a los consejos no surgió del propio gobierno sino de los trabajadores. En todo caso lo que sí quería la socialdemocracia era, por medio de esta inclusión constitucional, bajar la radicalización de las demandas. A partir de ese momento se identifican en los debates algunas propuestas en torno a los consejos, de manera más radical por los llamados socialdemócratas independientes, que buscaban darles el mayor poder politico posible. Incluso el gobierno llegó a presentar un borrador donde se incluía su regulación. Sin embargo, no fue sino hasta que Sinzheimer participó de la redacción del artículo que los consejos encontrarian su entrada definitiva en la Constitución. Su aporte, entonces, no fue tanto el de haber traído la idea de consejos a la Asamblea sino que sería, como veremos, el de integrar esa idea de consejos -que por sí sola no era tan significativa en su pensamiento- con la más profunda de autodeterminación y de democracia económica.

El texto definitivo del artículo $165^{68}$ terminaría estableciendo en sus primeras lineas un llamado a los trabajadores a participar en comunidad con los empleadores y con iguales derechos en la regulación de salarios y de condiciones de empleo así como también en el desarrollo general de la economía y de las fuerzas productivas. El artículo institucionalizaba consejos de trabajadores (Arbeiterräte) y consejos económicos (Wirtschaftsräte). Los primeros estaban destinados a organizarse en forma de pirámide en el lugar de trabajo, el distrito y a nivel nacional. Los segundos se conformarian de representantes de los consejos de trabajadores de distrito, los empleadores y otros grupos, organizándose también a nivel distrital y nacional. Finalmente, se preveía un Consejo Nacional Económico (Reichswirtschaftsrat) que coordinaria la toma de decisiones en los consejos más pequeños y que tendrían alguna influencia limitada en la esfera politica, con derecho a presentar propuestas de ley y de comentar proyectos legislativos.

68 Artículo 165.- Los obreros y empleados serán llamados a colaborar al lado de los patronos y con igualdad de derechos en la regulación de las condiciones laborales y retributivas, así como en todo el desarrollo económico de las fuerzas productivas. Serán reconocidos las agrupaciones de ambas clases y sus acuerdos. Para defensa de sus intereses sociales y económicos tendrán los obreros y empleados representaciones legales en consejos obreros de empresa, así como en los consejos obreros de distrito, agrupados por sectores económicos, y en un consejo obrero del Reich. Los consejos obreros de distrito y el consejo obrero del Reich, unidos con las representaciones de los patronos y demás clases interesadas, formarán consejos económicos de distrito y un consejo económico del Reich con competencia sobre todas las cuestiones de orden económico y de cooperación en la ejecución de las Leyes socializadoras. Los consejos económicos de distrito y del Reich estarán constituidos de forma que se hallen representados en ellos todos los grupos profesionales importantes, en proporción de su importancia económica y social. Los proyectos de Leyes político-sociales y político-económicos de interés fundamental deberán, antes de ser presentados, ser sometidos por el Gobierno del Reich a informe del consejo económico del Reich. A su vez, el consejo económico tendrá derecho a solicitar por sí mismo tales proyectos de Ley. Si el Gobierno no los hiciesen suyos, habrá, no obstante, de presentarlos al Reichstag con indicación de su parecer. El consejo económico podrá, a través de uno de sus miembros, defender ante el Reichstag sus proyectos. Podrán ser transferidas a los consejos obreros y a los consejos económicos facultades de control y de administración en las esferas competenciales que tengan asignadas. Es de competencia exclusiva del Reich regular la organización y atribuciones de los consejos obreros y de los consejos económicos, así como sus relaciones con otras corporaciones sociales autónomas. 


\section{CONSTITUCIONALISMO SOCIAL COMO DEMOCRACIA ECONÓMICA}

Ahora bien, para comprender mejor el alcance de la propuesta socialdemócrata y en particular de las ideas de Sinzheimer sobre el nuevo articulado es necesario recurrir a los discursos donde fundamenta estas propuestas en la Asamblea como también a su obra. En esta instancia nos concentraremos principalmente en los primeros ${ }^{69}$. Cabe recordar que todo discurso en el seno de una Asamblea, y en particular una constitucional, tiene muchas limitaciones. Se trata de un registro mucho más estratégico que ideológico. Muchas veces condicionado por el tiempo, el auditorio, las estrategias politicas, etc. Sin embargo, el objetivo de este artículo es el de indagar por el sentido que en ese momento específico se le quiso dar a los conceptos centrales de la propuesta constitucional. No, como ya se adelantó, en búsqueda de un argumento "originalista", sino con el fin de contribuir a una historia intelectual sobre el constitucionalismo social de Weimar.

Dos discursos de Sinzheimer en la Asamblea son la clave para acceder a estos elementos: el que diera el 2 de junio ante la comisión constitucional ${ }^{70}$ y el del 21 de julio ante el pleno de la Asamblea ${ }^{71}$. Los destinatarios y objetivos de estos dos igualmente apasionados discursos eran diferentes: en el primero Sinzheimer se dirige a sus colegas en la comisión constitucional al final de la primera lectura y en el segundo le habla a la Asamblea en pleno al final de la segunda lectura. En ambos casos Sinzheimer había sido elegido como orador (Berichterstatter) encargado de informar y fundamentar lo incorporado a la nueva sección económica de la Constitución.

Sinzheimer comenzó el discurso del 2 de junio con una impactante confesión: que ni él ni sus colegas del SPD creían que la idea de consejos fuera realizable. Lo que veía era una profunda demanda en la población por la introducción de la idea de consejos. Como si se tratara de idea redentora o de salvación, como si con la sola regulación de los consejos se solucionaran la miseria y los demás problemas sociales en los que estaba sumergida Alemania. Los consejos, desde su punto de vista, no iban a remediar nada por sí mismos. Sin embargo lo que sí podía traer aires nuevos a la Constitución era la idea que se encontraba detrás de ellos: la de democracia. La búsqueda por la autodeterminación de los trabajadores.

Para demostrarlo, Sinzheimer continuó su discurso con una suerte de análisis conceptual de los consejos (en alemán "Rate") distinguiendo diversos significados: el de dictadura de clase -como la de los consejos bolcheviques-, pero también el sentido de autodeterminación, que se había hecho realidad durante los días de la revolución de noviembre. La crítica de Sinzheimer se dirige a la primera acepción, porque no la concibe como compatible con la democracia

69 Aunque cabe destacar que Sinzheimer dio dos discursos más en 1919 que se refieren al tema de los consejos: el que pronunciara en la conferencia del partido socialdemócrata en marzo de 1919 y en el Parteitag en Weimar del 10 al 15 de junio de 1919. El primero disponible en Protokolle der Sitzungen des Parteiausschusses, Bd. 2. O. O.,o. J. [Berlin 1921], $651-653$ y el segundo en Protokolle der Verhandlungen des arteitages der Sozialdemokratischen Partei Deutschlands, Berlin 1919, 406-420.

70 Stenographische Berichte...T. 336, p. 393 y ss.

71 Stenographische Berichte...T. 328, p. 1750 y ss. 
parlamentaria. Pero también el discurso deja entrever otra batalla de sentido, que en este caso es contra de la idea de consejos profesionales (Berufsräte). Sinzheimer se oponía a la idea de que se le diera a grupos de profesionales poder de decisión sobre la politica económica, algo que algunos diputados estaban dispuestos a proponer. Así es que, al igual que lo haría luego frente a la Asamblea en pleno, afirmó que su propuesta se encontraba en el medio de ambos sistemas (el bolchevique y el de consejos profesionales) entendiendo a los consejos como un medio de autodeterminación social (sozialen Selbstbestimmung) ${ }^{72}$.

Esta idea de autodeterminación, sin embargo, no era nueva en el pensamiento de Sinzheimer sino que debe ser comprendida a la luz de su pensamiento sobre el derecho laboral elaborado años antes. Cuando Sinzheimer habla de "autodeterminación" está pensando en el tipo de autoregulación propia de los convenios colectivos o Tarifvertrag, aunque su concepto de autonomía no se reducía sólo a esos acuerdos. Se trata de la idea de un derecho creado de manera espontánea, sin intervención del Estado. Esto lo había trabajado profundamente en su obra de 1916 Ein Arbeitstarifgesetz. Die Idee der sozialen Selbstbestimmung im Recht (Una ley de convenios colectivos. La idea de autodeterminación social en el derecho) y es además un concepto que recupera del pensamiento de Gierke ${ }^{73}$. En este contexto, el derecho laboral debía servir como un medio para garantizar la participación de los trabajadores en las decisiones que los afectaban, en otras palabras, para garantizar la democracia económica. Para Sinzheimer esta autonomía prevalecía incluso sobre la legislación estatal, ya que entendía que esta última debía ser subsidiaria de la legislación autónoma. Sin duda, una idea absolutamente revolucionaria para su tiempo ${ }^{74}$.

Ahora bien, esta idea de autodeterminación que rescata del pensamiento sobre los consejos la completa en su discurso con la noción de Constitución económica. Sinzheimer entendía que a la Constitución del Estado (Staatsverfassung) debía complementarla una Constitución social (Gesellschaftsverfassung) en la cual los principales actores fueran las fuerzas sociales autónomas. Esta última no era una institución estatal, sino que debía ser entendida en un sentido más restringido como una Constitución "económica" (Wirtschaftsverfassung), que tomaba su forma de ambos tipos de consejos: los de trabajadores y los económicos. Así, las fuerzas autónomas -reguladas por el

72 Por supuesto esta conceptualización debe ser complementada con una lectura detallada de las obras de Sinzheimer de principios de siglo. En ellas encontramos una muy profunda teorización acerca del carácter democrático de la idea de convenio colectivo de trabajo que se asemeja mucho a la planteada en la Asamblea. Sinzheimer no defendia la idea de consejos por sí misma sino la idea de "autorregulación regulada" que había detrás de ella y que ya había esbozado en un famoso libro de 1907 titulado "Der korporative Arbeitsnormen Vertrag". Ver también una recepción de estas ideas en Ernst Fraenkel, "Rätemythos und soziale Selbstbestimmung”, Politik und Zeitgeschichte, April 1971, Nr. B 14/71.

73 Ver Hugo Sinzheimer, “Otto von Gierkes Bedeutung für das Arbeitsrecht”, en: Otto KahnFreund y Thilo Ramm (edit.), Hugo Sinzheimer. Arbeitsrecht und Rechtssoziologie. Gesammelte Aufsätze und Reden, Europäische Verlagsanstalt, Frankfurt am Main y Köln, 1976, pp. 402-407. Cabe aclarar que la visión de Sinzheimer sobre las asociaciones, a diferencia de la de Gierke, se aleja de la noción de corporativismo que encontraría eco en la Italia fascista. Su idea se acerca mucho más a la noción de Verbände (asociaciones) que tiene una larguísima tradición en Alemania.

${ }^{74}$ Otto Kahn-Freund, Labour Law and Politics in the Weimar Republic, op. cit. 
Estado- serían el engranaje central de la Constitución económica, proponiendo directivas y límites a la economía privada. La Constitución económica, en definitiva, la entiende Sinzheimer como necesaria para acabar con la subordinación del trabajo al capital. Idea que se encuentra también en su propia concepción del rol del derecho laboral ${ }^{75}$.

En el mismo discurso, aunque no sin cierta ambigüedad ${ }^{76}$, Sinzheimer se refirió a las funciones que tendrían los consejos dentro de la economía y a sus relaciones con otras organizaciones, como los sindicatos. La regulación de los salarios y las condiciones de trabajo eran la responsabilidad primaria de los consejos de trabajadores. Aquí Sinzheimer incorporó una importante distinción entre los sindicatos, consejos y otras asociaciones voluntarias: bajo ninguna circunstancia los acuerdos de trabajadores podrian representar un sustituto de los convenios colectivos de trabajo (Tarifuertrag). Esta relación podría ser resumida en la frase "complemento si, reemplazo no"77.

En síntesis, la estrategia de este primer discurso de Sinzheimer es la de poner en escena la idea de autodeterminación detrás de la de consejos y a partir de ella, destacar el rol de la Constitución económica en la realidad de Weimar: la de funcionar como una barrera para la libre decisión de la esfera económica privada. En otras palabras lo que desde su perspectiva la realidad de 1919 pedía era acabar con el "lujo de un sector privado desenfrenado"78 y para eso era necesario diseñar una forma institucional de intervención en la economía haciendo prevalecer sobre el sector privado (Privatwirtschaft) la economía popular (Volkswirtschaft).

Esta es la idea fuerte que dio inicio al segundo discurso que dio en la Asamblea, en este caso frente al pleno, unas semanas más tarde. La fuerza persuasiva en esta ocasión era aún más fuerte, tal vez porque se trataba de defender el trabajo realizado por la comisión constitucional frente a todos los miembros de la Asamblea. Como hiciera ante la comisión, Sinzheimer volvió sobre la necesidad de regular la libertad económica del individuo y de garantizar su función social. Función que también se aplicaba al derecho de propiedad, el derecho de herencia y a la garantía de contratación. A partir de esta idea fundamentó las tres incorporaciones principales de la quinta sección de la segunda parte de la Constitución: i) la protección y regulación de la vida económica individual (Art. 151, 152, 153 y 154); ii) la protección de la fuerza de trabajo como un bien jurídico especial (Art. 157-163) y, lo más importante, iii) la creación de una Constitución económica por medio de la introducción de los consejos en la Constitución (Art. 165).

Sinzheimer realizó un detallado comentario sobre las tres ideas pero le dio una mayor trascendencia a la tercera, que presentó como la principal contribución de la comisión constitucional a la Asamblea. En este punto repitió

75 Hugo Sinzheimer, “Die Idee des Arbeitsrechts", ArbR, 1923, pp. 721-730 y "Der Kampf um das neue Arbeitsrecht", en: Otto Kahn-Freund y Thilo Ramm (edit.), Hugo Sinzheimer. Arbeitsrecht und Rechtssoziologie. Gesammelte Aufsätze und Reden, Europäische Verlagsanstalt, Frankfurt am Main y Köln, 1976, pp. 91-99.

76 Gerhard Ritter, "Die Entstehung des Räteartikels 165 der Weimarer Reichsverfassung”, op. cit.

77 Otto Kahn-Freund, Labour Law and Politics in the Weimar Republic, op. cit., p. 89.

78 Stenographische Berichte... T. 336, p. 393. 
algunas ideas del primer discurso ante la comisión pero les sumó una profunda ilustración teórica sobre la lógica de los consejos de trabajadores y los consejos económicos. Esta organización, entendía, se basaba en dos fuerzas: la de oposición (Gegensatz) y la de comunidad (Gemeinschaft). La primera representaba la contradicción entre capital y trabajo y por lo tanto requería de una igual participación en los consejos de ambas partes: trabajadores y empleadores. La segunda explicaba el interés común en la producción y su objetivo era el de incrementar la productividad. Estas dos tendencias, propias de la vida económica, encontraban su lugar en los consejos de trabajadores y en los económicos, respectivamente. Y formaban parte de la Constitución económica y mediante ella, permitían la participación de los trabajadores en la vida económica.

Estas instituciones, sin embargo, no estaban pensadas para reemplazar a la democracia económica sino para complementarla79. En ese sentido, son numerosas las referencias respecto de que se había elegido no darles a los consejos todo el poder político sino una "influencia política". Aquí podemos identificar en Sinzheimer un nuevo intento por clarificar el concepto de consejo que estaba usando. Tal vez porque sabía que la mayoría de los miembros de la Asamblea hubieran rechazado esta propuesta por temor a la inclusión de una suerte de consejos bolcheviques en la Constitución. Los consejos, en efecto, detentaban poder político porque tenian el derecho de ser oídos antes de la introducción de cualquier proyecto de ley con contenido socio-político o económico y podían ser representados por los miembros del Consejo Económico del Reich en el Parlamento ${ }^{80}$. Sin embargo, no reemplazaban al parlamento, sino que en todo caso, estaban pensados para trabajar junto a él.

Así, nuevamente vemos en este discurso cómo Sinzheimer apunta el significado político de los consejos y no tanto a su implementación práctica. Su lectura va más allá de la coyuntura de la demanda por los consejos y busca apuntalar la idea de participación de los trabajadores en la Constitución. Participación que hasta 1918 les era un asunto absolutamente ajeno y que el sistema de consejos venía de alguna manera a cambiar ${ }^{81}$. A Sinzheimer le interesaba destacar a los consejos en su relación con el principio de autodeterminación y en esta ocasión, también su mecánica dentro de lo que daba a llamar Constitución económica. Este concepto que tal vez no fue del todo entendido por la Asamblea, trascendería estos discursos de 1919 y aparecería nuevamente en posteriores obras de Sinzheimer ${ }^{82}$.

79 Esta idea aparece también desarrollada en Hugo Sinzheimer, Das Rätesystem: Zwei Vorträge zur Einführung in den Rätegedanken, Union Druckerei und Verlagsanstalt, Frankfurt am Main, 1919.

80 El consejo económico del Reich era para Sinzheimer como un gran parlamento en la vida económica. Karl Albrecht, Hugo Sinzheimer in der Weimarer Nationalversammlung: Sein Beitrag zum wirtschaftlichen Rätesystem und zu den arbeits- und wirtschaftsrechtlichen Grundrechten der Reichsverfassung, op. cit.

81 Karl Albrecht, Hugo Sinzheimer in der Weimarer Nationalversammlung: Sein Beitrag zum wirtschaftlichen Rätesystem und zu den arbeits- und wirtschaftsrechtlichen Grundrechten der Reichsverfassung, op. cit.

82 El concepto de Constitución económica ya aparecería en algunas obras de Sidney y Beatrice Webb de 1897 que Sinzheimer bien pudo conocer (Dukes, 2008). 
Cabe destacar un último elemento que aparece en este discurso y que merece ser analizado a la luz del contexto de Weimar. En lo que respecta exclusivamente a los derechos incorporados en esta sección de la Constitución el discurso de Sinzheimer fue bastante más parco que en otras ocasiones. En efecto, se limitó a explicar lo que era la posición oficial del SPD en materia de operatividad directa: estos derechos eran tan sólo "bases programáticas" (programmatische Grundlage) y que por lo tanto no podian ser invocados en sede judicial sin ley reglamentaria del Parlamento. Aquí se vuelve importante la hipótesis sobre un auditorio imaginario y futuro del discurso de Sinzheimer: los tribunales y la academia ${ }^{83}$. Era común que tanto la justicia como la academia jurídica de entonces recurrieran a los debates parlamentarios o, como en este caso, a los debates constituyentes, como fuente de interpretación. Y en este punto, lo que a la socialdemocracia le importaba era restringir el papel de la justicia de Weimar -antidemocrática y conservadora- a la hora de interpretar estos nuevos derechos. Apostaban al poder legislativo, en el que tenian garantizada entonces una mayoria, no al poder judicial ${ }^{84}$, que se encargaría durante la República de frenar todo tipo de legislación social. En palabras de Otto Kahn-Freund: en Weimar, ser democrático era ser positivista ${ }^{85}$.

\section{CONCLUSIONES}

Una mirada detallada a los debates de la Asamblea Nacional de Weimar y en particular a las intervenciones de Hugo Sinzheimer en los mismos nos permite releer sus disposiciones sobre el modelo de Estado y de derechos sociales bajo una nueva luz. Es cierto que el artículo 165 y la institucionalización de los consejos ocupan un rol importante en el diseño de constitucionalismo social que se pensó en Weimar, pero no son ni ese diseño específico ni mucho menos su escasa performance posterior, los que habilitan las lecturas más interesantes. Son precisamente los discursos de Sinzheimer y sus ideas en torno a la autodeterminación, provenientes de su concepción sobre el derecho laboral, los que permiten una relectura del constitucionalismo social de Weimar en términos de democracia económica. En otras palabras, no sería la idea de consejo en sí misma sino la de autodeterminación, el mayor aporte de Sinzheimer al trabajo de la Asamblea de Weimar.

Esta es sin duda una idea novedosa, incluso revolucionaria para su época. Posiblemente lo fuera en demasía. En efecto, estas disposiciones no tuvieron

83 Karl Albrecht, Hugo Sinzheimer in der Weimarer Nationalversammlung: Sein Beitrag zum wirtschaftlichen Rätesystem und zu den arbeits- und wirtschaftsrechtlichen Grundrechten der Reichsverfassung, op. cit.

84 Sinzheimer concebía la idea de tribunales del trabajo, es decir un fuero específico, con procesos específicos, pero era consciente de que los tribunales requerian de un cambio en su composición, de jueces con una concepción más próxima a los pilares del derecho social.

85 Ewan McGaughey y Otto Kahn-Freund, "Autobiographical Memories of the Weimar Republic: A Conversation with Wolfgang Luthardt (February 1978)", disponible en: https://ssrn.com/abstract=2768439, 2016. Sobre el rol del positivismo y otras teorias en la República de Weimar me ocupé en Leticia Vita, "La noción de principios jurídicos en la teoría del derecho de Hermann Heller", Isonomía. Revista de teoria y filosofia del derecho, $\mathrm{n}^{\circ} 43,2015$, pp. 49-75. 
mayor efectividad en el tiempo. Lo que contribuyó también a dejar parte de esta historia intelectual en el olvido. De todas formas no puede decirse que ninguna de estas ideas haya trascendido en el tiempo. Se podría pensar que las nociones de autodeterminación y democracia económica pervivieron en Alemania a nivel legislativo. Las leyes de codeterminación de los trabajadores en las empresas, la participación de los empleados en ciertas decisiones económicas en Alemania, pueden rastrearse a los tiempos de Weimar.

Por otra parte, no se nos puede pasar por alto el hecho de que el artículo 165 pertenece mucho más a la parte orgánica de la Constitución que a la dogmática. No se trata de un artículo que regule derechos, sino que se ocupa de instituciones que tienen un impacto en la distribución de poder político y económico. Por distintas razones institucionales, de contexto, este artículo se "coló" entre los derechos fundamentales resultando en algo totalmente nuevo. Que la idea de democracia económica haya sido anclada junto con los derechos fundamentales permite una lectura más compleja de los mismos. En otras palabras, invita a interpretar el derecho al trabajo, la libertad de asociación, el derecho a la educación o la función social de la propiedad en relación con la idea de democracia económica. La regulación de las relaciones laborales y de los aspectos económicos que impactan en los derechos no tiene por qué ser ajena a estas disposiciones constitucionales.

Asimismo, el hecho de que gran parte de las disposiciones de la Constitución en materia social no hayan logrado los objetivos propuestos no desmerece el trabajo de la Asamblea. Muchas de esas instituciones provenian de muy buenas ideas. Lo que no encontraron fue un eco en la sociedad que tenía la responsabilidad de implementarlas. De igual manera, el hecho de que la Constitución de Weimar haya sucumbido a las fuerzas antidemocráticas que sostuvieron al régimen nazi no la convierte necesariamente en una Constitución "fallida", en todo caso la podremos leer como una Constitución sin republicanos que la defendieran ${ }^{86}$. Lo que este artículo ha intentado demostrar es que sólo si, como mínimo, dejamos en suspenso esa interpretación de la Constitución de Weimar como Constitución fallida, podremos dar cuenta cabalmente de lo que significó en términos de constitucionalismo social.

Finalmente, lo que esta relectura del constitucionalismo social de Weimar habilitaria es complejizar nuestras investigaciones en torno a los sentidos de Estado social y derechos sociales que trascendieron al texto de 1919. Queda por indagar si esta idea de democracia económica logró trascender el contexto de 1918-19 o bien quedó anclada en disposiciones ineficaces y discursos de la época. Acaso haya sido el derecho laboral del momento un ámbito donde muchas de estas ideas tuvieron una proyección mayor que en el derecho constitucional. Lo claro es que todavía queda mucho por revisar respecto de los "sentidos" del constitucionalismo social de Weimar que fueron traducidos a otros contextos.

Por último, es casi imposible no leer las palabras de Hugo Sinzheimer sobre la Constitución económica, la autodeterminación y la democracia económica sin la tentación de pensar cuál sería la adaptación de estas ideas para tiempos como los nuestros. En un contexto donde nuestras constituciones sociales son

86 Ver para el ámbito hispanohablante Leonardo Álvarez Álvarez, "La Constitución de Weimar ¿una República sin republicanos?”, Historia constitucional, n¹2, 2011, pp. 443-460. 
socavadas por la globalización y la concentración del poder económico, la llamada por una democracia económica como medio de emancipación humana es actualmente válida. Siguiendo las palabras de uno de los discípulos más queridos de Sinzheimer "leemos su inspiradora exposición sobre la 'constitución económica' de la misma manera en que se leen los grandes libros utópicos y novelas políticas del pasado Europeo, y deberiamos seguir leyéndolos hasta tanto los seres humanos se sientan obligados a reflexionar sobre las formas de organización politica"87.

\section{BIBLIOGRAFÍA}

Albrecht, K. (1970). Hugo Sinzheimer in der Weimarer Nationalversammlung: Sein Beitrag zum wirtschaftlichen Rätesystem und zu den arbeits- und wirtschaftsrechtlichen Grundrechten der Reichsverfassung. Dissertation. Frankfurt am Main: Universität Frankfurt am Main.

Álvarez Álvarez, L. (2011). La Constitución de Weimar ¿una República sin republicanos?. Historia constitucional: Revista Electrónica de Historia Constitucional, 12:443-460.

Anschütz, G. (1923). Drei Leitgedanken der Weimarer Reichsverfassung. Tübingen: Mohr.

Anschütz, G. y Thoma, R. (edit.) (1932). Handbuch des Deutschen Staatsrechts. Tübingen: Mohr.

Anschütz, G. (1933). Die Verfassung des Deutschen Reiches vom 11.August 1919. Berlin: Stilke.

Apelt, W. (1946). Geschichte der Weimarer Verfassung. München: Biederstein.

Bendix, K. (2002). Die Arbeit des Verfassungsausschusses. achter Ausschuss der verfassungsgebenden Nationalversammlung von Weimar. Frankfurt am Main: Peter Lang.

Benöhr, H. (1989). Hugo Sinzheimer (1875-1945). En: B., Diestelkamp y M. Stolleis (edit.) Juristen an der Universität Frankfurt am Main (pp. 67-83). BadenBaden: Nomos.

Beyersdorff, H. (1928). Die Staatstheorien in der verfassunggebenden deutschen nationalversammlung von 1919. Coburg: Coburger Tageblatt.

Blanke, S. (2005). Soziales Recht oder kollektive Privatautonomie? Hugo Sinzheimer im Kontext nach 1900. Tübingen: Mohr.

Blau, J., (1980). Sozialdemokratische Staatslehre in der Weimarer Republik. Marburg: Verlag Arbeiterbewegung und Gesellschaftswissenschaft.

Bollmeyer, H. (2007). Der steinige Weg zur Demokratie. Die Weimarer Nationalversammlung zwischen Kaiserreich und Republik. Frankfurt: CampusVerl.

Bracher, K. D. (1963). Die Entstehung der Weimarer Verfassung. Hannover: Niedersächsische Landeszentrale für Politische Bildung.

87 Otto Kahn-Freund, Labour Law and Politics in the Weimar Republic, op. cit., p. 88. 
Caldwell, P. (1997). Popular sovereignty and the crisis of German Constitutional Law: the theory and the practice of Weimar constitutionalism. Durham: Duke University Press.

Caldwell, P. y Scheuerman, W. (2000). From Liberal Democracy to fascism: Legal and Political thought in the Weimar Republic. Boston: Humanities Press.

Gusy, C. (ed.) (2000). Demokratisches Denken in der Weimarer Republik. BadenBaden: Nomos.

De Wolf, A. (2015). Hugo Sinzheimer und das jüdische Gesetzesdenken im deutschen Arbeitsrecht. Berlin: Hentrich \& Hentrich Verlag.

Dukes, R. (2008). Constitutionalizing Employment Relations: Sinzheimer, KahnFreund and the Role of Labour Law. Journal of Law and Society, 35 (3), 341363. Disponible en: doi:10.1111/j.1468-2230.2009.00741.x.

Dyzenhaus, D. (1999). Legality and Legitimacy: Carl Schmitt, Hans Kelsen and Hermann Heller in Weimar. Oxford: Oxford University Press.

Dyzenhaus, D. (edit.) (1998). Law as Politics: Carl Schmitt's Critique of Liberalism. Durham: Duke University Press.

Fraenkel, E. (1958). Hugo Sinzheimer. Juristenzeitung, 15: 457-46.

Fraenkel, E. (1971). Rätemythos und soziale Selbstbestimmung. Politik und Zeitgeschichte, B 14/71: 25.

Gierke, O. (1888). Entwurf eines bürgerlichen Gesetzbuches und das Deutsche Recht. Leipzig: Dunker \& Humblot.

Gierke, O. (1889). Die soziale Aufgabe des Privatrechts. Berlin: Springer.

Grimm, D. (1990). Die Bedeutung der Weimarer Verfassung in der deutschen Verfassungsgechichte. Heildelberg: Stiftung Reichspräsident-Friedrich-EbertGedenkstätt.

Groh, K. (2010). Demokratische Staatsrechtslehrer in der Weimarer Republik. Tübingen: Mohr.

Gusy, C. (1991). Weimar, Die wehrlose Republik?: Verfassungsschutzrecht und Verfassungsschutz in der Weimarer Republik. Tübingen: Mohr.

Gusy, C. (1994). Die Entstehung der Weimarer Reichsverfassung. Juristenzeitung (JZ), 49 (15):753-763.

Gusy, C. (1997). Die Weimarer Reichsverfassung. Tübingen: Mohr.

Heinrichs, H. et. al. (1993). Deutsche Juristen jüdischer Herkunft. München: Beck.

Herrera, C. M. (2002a). Les juristes de gauche sous la République de Weimar Les juristes de gauche sous la république de Weimar. Paris: Kimé.

Herrera, C. M. (2002b). Derecho y socialismo en el pensamiento jurídico. Bogotá: Universidad Externado de Colombia.

Herrera, C. M. (2011). La Constitution de Weimar et la pensée juridique française: réceptions, métamorphoses, actualités. Paris: Kimé.

Horst, D. (1975). Rätedemokratische Modelle. Studien zur Rätediskussion in Deutschland 1918-1919. Meisenheim am Glan: Anton Hain. 
Huber, E. (1978). Deutsche Verfassungsgeschichte seit 1789. T. 6 y 7. Stuttgart: Kohlhammer Verlag.

Jacobson, A. y Schlink, B. (edit.) (2000). Weimar: a Jurisprudence of crisis. Berkeley: University of California Press.

Jellinek, W. (1920). Revolution und Reichsverfassung. Jahrbuch des öffentlichen Rechts, 9: 1-128.

Kahn-Freund, O. (1981). Labour Law and Politics in the Weimar Republic. Oxford: Basil Blackwell Publisher.

Kaplan, L. y Koshar, R. (edit.) (2012). The Weimar moment: liberalism, political theology and law. Lanham: Lexington Books.

Kennedy, E. (2004). Constitutional Failure: Carl Schmitt in Weimar. Durham: Duke University Press.

Knorre, S. (1991). Soziale Selbstbestimmung und individuelle Verantwortung: Hugo Sinzheimer (1875-1945). Eine politische Biographie. Frankfurt am Main: Peter Lang.

Köster, F. (2003). Entstehungsgeschichte der Grundrechtsbestimmungen des zweiten Hauptteils der Weimarer Reichsverfassung. Göttingen: Cuvillier Verlag.

Kubo, K. (1999). Hugo Sinzheimer - Vater des deutschen Arbeitsrechts - Eine Biographie. Köln: Bund Verlag.

Luthardt, W. (1986). Sozialdemokratische Verfassungstheorie in der Weimarer Republik. Opladen: Westdeutscher Verlag.

Malowitz, K. (2003). Die Persönlichkeit des Staates und das Wesen der menschlichen Verbände. Anmerkungen zur Genossenschaftstheorie Otto von Gierkes und ihrer Rezeption durch Hugo Preuß und Hugo Sinzheimer. En: M. Gangl. (edit.). Linke Juristen in der Weimarer Republik (pp. 121-145). Frankfurt am Main: Peter Lang.

McGaughey, E. y Kahn-Freund, O. (2016). Autobiographical Memories of the Weimar Republic: A Conversation with Wolfgang Luthardt (February 1978). Disponible en: https://ssrn.com/abstract=2768439.

Menger, A. (1890). Das bürgerliche Recht und die besitzlosen Volksklassen. Eine Kritik des Entwurfs eines Bürgerlichen Gesetzbuches für das Deutsche Reich. Tübingen: H. Laupp.

Möller, H. (2004). Die Weimarer Republik. Eine unvollendete Demokratie. München: DTV.

Mommsen, W. (1996). The Rise and Fall of Weimar Democracy. Chapel Hill: University of North Carolina Press.

Mommsen, W. (1959). Max Weber und die deutsche Politik: 1890-1920. Tübingen: Mohr.

Mouffe, C. (edit.) (1999). The Challenge of Carl Schmitt. London: Verso.

Müller, C. (2015). Hugo Sinzheimer (1875-1945). Selbstorganisation und Selbstverwaltung im Arbeitsrecht. En D., Lehnert (edit.). Vom Linksliberalismus zur Sozialdemokratie. Politische Lebenswege in historischen Richtungskonflikten 1890-1945 (pp. 146-174). Köln: Böhlau. 
Nawiasky, H. (1920). Die Grundgedanken der Reichsverfassung. München: Duncker \& Humblot.

Pauly, W. (2004). Grundrechtslaboratorium Weimar. Zur Entstehung des zweiten Hauptteils der Reichsverfassung vom 14. August 1919. Tübingen: Mohr.

Gordon, P. y McCormick, J. (eds.) (2015). Weimar Thought: A Contested Legacy. Princeton: Princeton University Press.

Pinto, J. (2000). Carl Schmitt y la reivindicación de la politica. Buenos Aires: Editorial Universitaria del Plata.

Pohl, T. (2002). Demokratisches Denken in der Weimarer Nationalversammlung. Hamburg: Dr. Kovač.

Preuß, H. (1924). Um die Reichsverfassung von Weimar. Berlin: Mosse.

Preuß, H. (1926). Staat, Recht und Freiheit. Aus 40 Jahren deutscher Politik und Geschichte. Tübingen: Mohr.

Preuß, H., (1923). Deutschlands republikanische Reichsverfassung. Berlin: Neuer Staat.

Ritter, G. (1994). Die Entstehung des Räteartikels 165 der Weimarer Reichsverfassung. Historische Zeitschrift, 258:73-112.

Römer, W. (1921). Die Entwickelung des Rätegedankens in Deutschland. Berlin: Ebering,

Scheuerman, W. (1999). Carl Schmitt: The End of Law. Lanham: Rowman\& Littlefield.

Schulze, H. (1998). Weimar. Deutschland 1917-1933. Berlin: Siedler.

Sinzheimer, H. (1919). Das Rätesystem: Zwei Vorträge zur Einführung in den Rätegedanken. Frankfurt: M.Union Druckerei und Verlagsanstalt.

Sinzheimer, H. (1923). Die Idee des Arbeitsrechts. ArbR, Sp. 723.

Sinzheimer, H. (1976a). Der Kampf um das neue Arbeitsrecht. En: O. KahnFreund y Ramm, T. (edit.). Hugo Sinzheimer. Arbeitsrecht und Rechtssoziologie. Gesammelte Aufsätze und Reden (pp. 91-99). Frankfurt am Main y Köln: Europäische Verlagsanstalt.

Sinzheimer, H. (1976b). Otto von Gierkes Bedeutung für das Arbeitsrecht. En: En: O. Kahn-Freund y Ramm, T. (edit.). Hugo Sinzheimer. Arbeitsrecht und Rechtssoziologie. Gesammelte Aufsätze und Reden (pp. 402-407). Frankfurt am Main y Köln: Europäische Verlagsanstalt..

Sommermann, K. (1997). Staatsziele und Staatszielbestimmungen. Tübingen: Mohr Siebeck.

Sontheimer, K. (1962). Antidemokratisches Denken in der Weimarer Republik. München: Dt. Taschenbuch Verl.

Stolleis, M. (2002). Geschichte des öffentlichen Rechts in Deutschland: Weimarer Republik und Nationalsozialismus. München: Beck.

Stolleis, M. (2013). Origins of the German Welfare State. Social Policiy in Germany to 1945. Heidelberg: Springen. 
Lindt, A. (1973). Friedrich Naumann und Max Weber. Theologie und Soziologie im wilhelminischen Deutschland. München: TEH.

Völkerling, F. (1959). Der deutsche Kathedersozialismus. Berlin: Verlag die Wirtschaft.

Völtzer, F. (1992). Der Sozialstaatsgedanke in der Weimarer Reichsverfassung. Frankfurt am Main: Peter Lang.

Theiner, P. (1983). Sozialer Liberalismus und deutsche Weltpolitik: Friedrich Naumann im Wilhelmischen Deutschland (1860-1919). Baden-Baden: Nomos Verlag.

Zachert, U. (2001) Hugo Sinzheimer: praktischer Wissenschaftler und Pionier des modernen Arbeitsrechts. Recht der Arbeit (RdA), 54: 104-109.

Ziegler, W. (1932). Die Deutsche Nationalversammlung 1919-20 und ihr Verfassungswerk. Berlin: Zentralverlag.

\section{FUENTES:}

Nationalversammlung (1919), Stenographische berichte über die Verhandlungen der Verfassunggebenden Deutschen Nationalversammlung, Berlin: Druck und Verlag der norddeutschen Buchdrucherei. Disponible en:

http://www.reichstagsprotokolle.de/rtbiiiaufauf_wv.html

Enviado el (Submission Date): 18/07/2017

Aceptado el (Acceptance Date): 25/09/2017 